\title{
FETAL MICROCHIMERISM AND PRENATAL DIAGNOSIS OF GENETIC DISORDERS
}

\section{ABSTRACT}

It is often require an invasive diagnosis based on karyotyping of cells from amniotic fluid, chorionic villi and cord blood in case of the fetus pathologies during pregnancy. The performance of these procedures has a risk of pregnancy complications or procedure-induced miscarriage. Therefore the investigators have nowadays been developing several approaches which would be capable to replace invasive diagnosis by alternative and safe non-invasive methods for detection of possible pregnancy pathology. Fetal microchimerism phenomenon and reliable strategies of fetal cells enrichment during early embryogenesis are reviewed. Fetal cells circulating in the peripheral blood of pregnant women has been described as a potential source of fetus genetic material in non-invasive prenatal diagnosis for chromosomal aberrations.

KEYWORDS: pregnancy, fetal microchimerism, chromosomal abnormalities, prenatal genetic screening

The present-day methods of fetal prenatal diagnosis consist of noninvasive and invasive approaches. Prenatal screening includes ultrasound analysis and non-invasive tests of maternal venous blood performed in clinic to assess rhesus-factor and gender of the fetus. The invasive approach is based on the analysis of fetal cells (FCs) using karyotyping method. To define the risk of genetic abnormalities FCs are thus obtained invasively using techniques such as chorionic villus and cord blood sampling or amniocentesis. Invasive tests in some cases leads to risk of pregnancy complications or procedure-induced miscarriage [1-4]. The immune phenotyping and genetic screening of FCs isolated from the blood of pregnant woman are among the approaches that can replace invasive fetal diagnosis.

The presence of FCs in maternal circulation occurs due to the phenomenon of transplacental transfusion, i.e. bi-directional transfer of cells between mother and fetus during pregnancy. It was originally assumed that the FCs begin migrating to maternal blood following the end of mesoblastic period of fetal hematopoiesis in the yolk sac [5]. FCs are formed initially in the yolk sac at 4 weeks of gestation during normal pregnancy. These cells are already capable to migrate into the maternal circulation. However, FCs do not circulate until 5 weeks' when the heart begins to beat [6]. The engrafted FCs represents a minor population in maternal blood. Their percentage ratio varies during gestation period depending on pregnancy trimester [7-9]. The number of FCs in maternal blood increases in the first trimester and drastically decreases after delivery [10-12].

The result of transplacental transfusion is the phenomenon of microchimerism (Mc). Mc is described as FCs engraftment in the maternal organism (fetal microchimerism, FMc) or maternal cells engraftment in fetus (maternal microchimerism, MMc). The cells can coexist in one organism despite being genetically different. The population of such cells that migrate and engraft in foreign organism is heterogenic. The cells expressing various markers are called the microchimeric cells (MCs) or the progenitor cells associated with pregnancy (PAPC) [13-16].

FMc is the physiological process which has been confirmed in the placental mammals [17]. Presence of FCs in the maternal blood during pregnancy plays an essential practical role in prenatal diagnosis of chromosomal aberrations. Choice of selective cellular and molecular-genetic markers of FCs would replace standard invasive diagnosis. The number of FCs in the maternal blood at normal pregnancy is however insufficient for genetic screening. In the case that chromosomal pathology is suspected the invasive technologies are used [18]. Thus, the FCs enrichment from maternal blood for genetic screening is still open or disputable so far. Moreover, new technologies of detection and isolation of FCs will allow use them as alternative source of stem cells in regenerative medicine.

The criteria for selecting proper type of FCs from maternal venous blood for non-invasive diagnosis include: short cell lifespan, absence or limited capacity for proliferation and presence of specific markers expressing on the surface of FCs but not on the surface of maternal cells. Further criteria are persistency of this type of cells at each pregnancy, a sufficient number of these cells at early stages of gestation; newer technologies for enrichment and culturing of the FCs [19]. Analysis of FCs at early stage of pregnancy should be based on the sensitive, effective and accessible express-methods of FCs identification and further isolation. Of today, the available methods of qualitative and quantitative detection of FCs in maternal blood are based on immunophenotyping and use of genetic markers. Among the methods allowing detect and isolate a minor population of FCs from maternal blood are the fluorescence-activated cell sorting (FACS) [20-23], magnetic-activated cell sorting (MACS) [22, 24, 25], fluorescent hybridization in situ (FISH) [24-29], immunocyto- and 
histochemistry $[21,27,28,30]$, polymerase chain reaction (PCR) [22, 27-29], chromosomal microarray analysis based on DNA chip [22-24, $26,31]$ and sequencing [32-36]. Using a combination of the above-listed methods, the researchers studied migration of FCs, both at the DNA and cellular levels.

\section{FETAL CELLS AS POTENTIAL MARKERS IN PRENATAL DIAGNOSIS OF GENETIC DISORDERS}

It is shown that the following types of FCs circulate in the maternal blood during pregnancy: trophoblast cells $[37,38]$, nucleated red blood cells (NRBCs) or erythroblast [39], lymphocytes [40] and fetal progenitor cells [14-16, 41-43]

Trophoblast cells. In 1982 C. Goodtellow and P. Taylor were first who isolated trophoblast cells from the blood of pregnant woman, using different gradients [37]. Special morphology of trophoblast cells allows identify them under microscope using immunocytochemical methods. Beginning from 6 weeks of gestation, the trophoblast cells were detected in the blood of pregnant women by flow cytometry using H315 antibodies to syncytiotrophoblasts [44]. In following investigations, the fraction of nucleus-free cells which probably originated from syncytiotrophoblasts are belonging to FCs. However the results of southern blot analysis using Y-specific probes showed that $\mathrm{H} 315$ antigen is detected on the surface of maternal lymphocytes and cannot be used as the FCs marker [30].

Other researchers showed that FCs have high expression of thymidine kinase (TK) gene at 10-21 gestation week that is atypical for the cells of healthy adult organism. Trophoblast cells, amniotic fluid cells, fetal and adult fibroblasts and fetal cord blood were analyzed for TK activity in comparison with adult peripheral blood samples. The highest enzyme activity was detected in the trophoblast cells, whereas no enzyme activity was seen in the adult peripheral blood samples. The number of cells with high TK activity was in the range of $30-60$ per 30 million of the total count cells per sample. In this research TK enzyme proposed a potential new marker to detect and enrich FCs from maternal blood [45]. However, trophoblast cells are rarely seen in maternal blood at pathology-free pregnancy [46] Anatomically, the trophoblast cells are placental origin. It is essential therefore to analyze fetal-origin rather than placental-origin material in order to identify chromosome fetal aberrations [47, 48].

During pregnancy the syncytiotrophoblast cells are migrated with blood to mother's lungs to undergo apoptosis. Fetal DNA liberate from lung capillaries to maternal blood like exogenous DNA - cell-free fetalderived DNA (cffDNA) [49]. Nowadays, the cffDNA is becoming the most suitable material for prenatal diagnosis of genetic abnormalities in the fetus. The cffDNA is abundant, stable and remains in maternal circulation for only a few days after pregnancy $[4,18,32,35,36,50]$.

Nucleated erythrocytes. During first two stages of embryonic hematopoiesis, mesoblastic and hepatic, there takes place an active erythropoiesis in the yolk sac, at the first two weeks of pregnancy and in the fetal liver since 5 gestation week [51]. Hence the nucleated erythrocytes, predominantly fetal origin, enter maternal blood as early as first trimester of pregnancy. These are the precursors of mature erythrocytes containing the nucleus. During first 10-20 weeks of pregnancy the amount of nucleated erythrocytes makes $10 \%$ of the total population of fetus blood cells compared to only $0.1 \%$ of adult organism [7-9].

For detection of fetal nucleated erythrocytes the antibodies against surface antigens transferrin (CD71) and glycophorin A (GPA) were used as well as the intracellular markers such as fetal and embryonic hemoglobin [52-55]. According to previous investigations, the fraction of erythroblasts can become potential object for analysis and performance of non-invasive diagnosis of the fetus pathology that might replace invasive analysis of amniotic fluid, fetal chorionic villi and cord blood during gestation period [56, 57].

It was found that lifespan of fetal erythroblasts, unlike fetal lymphocytes, is 120 days that makes impossible the survival of these cells in maternal blood from previous pregnancies $[58,59]$. The group of Choolani $M$. et al. described the protocol for isolation of fetal erythroblasts from the blood of pregnant women on 8-13 gestation weeks. The fetal nucleated erythrocytes from maternal blood were sorted by the MACS method using the panel of GPA, CD47, CD45, CD35, CD36 and CD71 antibodies. The obtained results revealed low CD71 expression on the FCs surface compared with erythroblasts of the adult organism [60]. However, other researchers did use CD71 as the marker of nucleated fetal erythrocytes [61-63]. Furthermore, the FISH and MACS methods, developed in previous experiments by other working groups for the isolation of fetus erythroblasts from maternal venous blood, showed low sensitivity [64].

Fetal lymphocytes. Fetal lymphocytes were first described in 1969 by the group of investigators headed by Walknowska J. [65]. For identifying fetal lymphocytes they carried out a cytology $Y$-chromosome test in the blood from healthy pregnant women carrying fetus of male gender. Using the FACS, other investigators sorted FCs from maternal blood using antibody to human fetal lymphocyte HLA-A2 antigen that express on the surface of fetal lymphocytes and does not express on the surface of maternal lymphocytes $[20,66]$. This method predisposes HLA typing in both parents and sensitive markers for identification of fetal lymphocytes among maternal lymphocytes. Furthermore, while analyzing fetal lymphocytes one should consider previous pregnancy histories. As a result of $\mathrm{Mc}$, the PAPC are capable engraft in maternal organism from previous pregnancies [42].

Fetal progenitor cells. Fetal hematopoietic stem cells (HSCs), multipotent mesenchymal stromal cells (MMSCs) [41] and endothelial progenitor cells [25] circulate in maternal blood during pregnancy. The investigators assume that FCs enter maternal blood prior to placenta formation [67]. According to the results of investigations, obtained on animal models [68], the progenitor FCs cells persist in maternal blood at early stage of fetus gestation after implantation and capable for multilinear differentiation [69]. It is assumed that FCs showed a capacity for regeneration at damaged tissue sites in the maternal organism during pregnancy and after childbirth [28, 43, 69-73]

Migration of progenitor FCs to the injured sites was showed on pregnant murine model with induced contact hypersensitivity reaction. The CD31+ endothelial progenitor cells were lining blood vessels in maternal sites of inflammation. In other words, neoangiogenesis occurs partly with an involvement of fetal endothelial progenitor cells during pregnancy [72].

Other investigations were carried out on murine models at damaged skin and spinal cord during pregnancy. Experimental results showed an increase of the FCs number only at the sites of injury in the comparison with control animals. Formation of blood vessels were observed around damaged sites indicating reparative potential of the FCs. It follows from this that microchimerism phenomenon can be linked with an increased proliferation of the FCs and not only with their migration [74]. On damaging liver and kidney, the FCs migrate to the center of damage area and differentiate into hepatocytes and tubular cells, respectively [69]. In the case of myocardium damaging they differentiate into the endotheliocytes, smooth muscle cells and cardiomyocytes [71].

A caesarean section scars were used as a model of wound healing in pregnancy, in human research. The presence of keratinocytes of fetal origin expressing cytokeratin in skin epidermis in women after caesarean section was showed by the FISH and immunocytochemistry. Additionally, the FCs expressed the transforming growth factor beta (TGF- $\beta$ ) as well as type I and III collagen, evidencing for involvement of FCs in maternal tissue reparation. FCs were absent in the abdominal wall of pregnant woman giving birth naturally [28].

In another investigations blood samples from women having firstpregnancy at 11-13 gestation weeks were collected for analysis. MACS method and panel of antibodies against CD34, CD105, CD141 and CD146 antigens were used for FCs enrichment. A population of cells carrying simultaneously the markers of trophoblast cells (cytokeratin) and CD105 were identified among FCs. Further investigations showed that antibodies to CD141 also demonstrate high expression to FCs [25, 26]. Trophoblast cells with phenotypes CD105 and CD141 are ascribed to the subpopulation of endovascular cells. Fetal endovascular trophoblast cells migrate 
into the myometrium of the placental bed, where they persisting maternal arteries and replacing maternal endothelial cells at early pregnancy stages, providing for transplacental transfusion between mother and fetus $[75,76]$. Simultaneous expression of endothelial and vascular markers on cell surfaces indicate that the FCs originate from ectodermal germ layer, adapt themselves in new vascular environment of mother's organism [77]. Combination of ectodermal (cytokeratin) and mesodermal (CD105 and CD 141) markers expressing themselves on the surface of trophoblast cells can become potential instruments for FCs enrichment from maternal blood in prenatal genetic diagnosis.

The populations of $\mathrm{CD} 34^{+}$cells were isolated from the venous blood of women who had undergone surgical termination of pregnancy (9-13 gestation weeks). According to the experimental results, the fraction of $\mathrm{CD} 34^{+}$cells was heterogeneous. The population consisted of stem cells and progenitor cells as well as pool of cells with adhesive properties and potential to differentiate in various maternal tissues (liver, heart, pancreatic gland and endothelial cells) [13, 78].

The group of Parant 0 . et al. obtained samples of fetal chorionic villi at normal delivery and pregnancy termination by caesarian section. Most of $\mathrm{CD} 34^{+}$cells in the bioptate had the fetal origin. Alongside, the cells with CD34+ phenotype showed high expression of CD31 marker and did not express CD117 and CD133, indicating their endothelial rather than hematopoietic origin [79]. The investigation of Bianchi D. et al. showed that FCs with $\mathrm{CD} 34^{+} \mathrm{CD} 38^{+}$phenotypes persisted in maternal blood mononuclear cells for as long as 20 years after childbirth [42]. It follows that CD34+ FCs can persist maternal blood from previous pregnancies and cannot be therefore clinically significant object for prenatal genetic diagnosis [80].

The fetal MMSCs were detected in maternal venous blood by the group of researchers O'Donoghue K. et al. They found that mononuclear cells isolated from the peripheral blood of woman at first trimester (7-13 gestation week), do not express on their surface CD45 and glycophorin A. Cell subpopulations were identified by means of the cytological method using the panel on monoclonal antibodies conjugated with alkaline phosphatase. According to the results of flow cytometry, the FCs had phenotype CD45-CD14-CD11a-CD49b-SH2 ${ }^{+} \mathrm{SH}^{+}{ }^{+}$imentin ${ }^{+} \mathrm{CD} 29^{+} \mathrm{CD} 49 \mathrm{e}^{+} \mathrm{CD} 106^{+}$ and HLA-II [74]. The mesenchymal origin of cells was confirmed by their further culturing and differentiation in vitro in the osteogenic and adipogenic directions.

Fetal MMSCs isolated from maternal blood at first trimester of pregnancy are viewed as an alternative source of stem cells for the regenerative medicine. Compared with the FCs obtained from abortive material the fetal MMSCs have longer telomeres and express transcriptional factors such as NANOG and Oct4, regulating self-renewal of undifferentiated embryonic stem cells. These proteins are the markers of cells capable for multilinear differentiation [81, 82]. Change of the level of Oct4 protein expression promotes cell differentiation. Interestingly, the transcriptional factor 0ct4 shows its activity additionally in the oocyte and prior to implantation process. Thus, the FCs migrating to maternal blood are lowdifferentiated and, probably, capable for self-renewal and pluripotency. The transcriptional Oct4 factor is not a compulsory sign of the pluripotent cells although the latter express a marker for cells maintaining their capacity for pluripotency [83]. Therefore search and identification of expression of the proteins such as 0ct4 is crucial for studying FCs regenerative potential.

\section{CULTURE OF FETAL CELLS}

Culture of FCs from maternal blood for prenatal diagnosis is an alternative approach of FCs enrichment and maternal cells depletion. It has been long believed that fetal nucleated erythrocytes can be chosen as a convenient object for culture. Along this direction, the group of Choolani M. et al. presented comparative characteristics of the conditions for erythroblasts culture. For this analysis they isolated erythroblasts from fetal chorionic villi and maternal peripheral blood of pregnant woman. The population of embryonic erythroblasts was characterized with low CD71 expression [60]. Therefore in this work the authors used the surface erythroid glycophorin
A (GPA) as a marker of fetal erythroblasts. The obtained results showed that fetal erythroblasts isolated from peripheral maternal blood had lower capacity for proliferation in vitro, compared with the erythroblasts isolated from fetal chorionic villi [84]. This determines the necessity of further investigations into developing culture conditions of nucleated erythrocytes from maternal blood for prenatal genetic diagnosis.

Embryonic and fetal development is accompanied with active angiogenesis. Vascular endothelial growth factor (VEGF) with highly affinity receptor tyrosine kinase (fetal liver kinase 1 - flk-1) promotes differentiation of endothelial cells from their progenitors $[85,86]$. The group of Gussin F. et al. assumed that endothelial progenitors of the fetal origin can migrate to maternal blood during pregnancy [87]. To check this hypothesis, a model of postnatal angiogenesis in vitro was developed. Venous blood samples of pregnant women carrying male fetus were collected on 15-20 of gestation week. The isolated mononuclear cells were cultured under conditions of induction into endothelial differentiation. Selection of FCs among maternal cells was performed under various cultivation terms. It is known that maternal precursor blood endothelial cells are formed at the early stage of culture (early outgrowth), and the colonies of fetal endothelial progenitors during 4-6 weeks of culture [88]. According to the obtained results, the endothelial progenitors were identified only in cell culture from maternal origin mononuclear cells of pregnant women but were not found among the cells of control samples. FISH analysis did not revealed cells with $X Y$ karyotype in the culture of endothelial progenitors. Thus, cultured cells were maternal origin [89].

\section{FETAL MICROCHIMERISIM AND MODERN MOLECULAR GENETIC METHODS IN PRENATAL DIAGNOSIS \\ OF GENETIC DISEASES}

\section{Chromosomal microarray analysis in prenatal diagnosis}

The chromosomal microarray analysis is used for identification of chromosomal aberrations, including minimal mutations, for detection of which the sensitivity of standard karyotyping method is insufficient. This is a full-genomic screening allowing assess deletions and duplications of DNA, single-nucleotide polymorphisms (SNP), localization and type of specific fetal genetic abnormalities.

There are two types of the microchips used in clinic: platforms for comparative chromosomal hybridization and SNP microchips which determine various kinds of genetic changes (trisomy and triploidy, etc.). This method is based on hybridization of fetal DNA with the chip containing fragments of the known DNA sequence. Data are processed by means of computer analysis. This method provides high sensitivity, quick obtaining of results (no cell culture is necessary) and standardized approach as compared with conventional cytogenetic analysis. The disadvantage of chromosomal hybridization and SNP microchips are their narrow specificity of analysis and impossibility to determine balanced inversions, balanced translocations and low-level mosaicism. However, to perform microarray analysis an invasive intervention is required as fetus DNA is isolated from the amniotic fluid or from fetal chorionic villi [31].

An alternative, non-invasive method was applied by Brinch $M$. and Hatt L.et al. The expression pattern of a subset of expressed genes was compared between fetal cells and maternal blood cells using stem cell microarray analysis. The leucocytes of maternal origin were depleted from the blood using MACS. FCs identified by XY FISH analysis were collected by laser capture microdissection. Then mRNA isolation was performed for the genetic screening. Initially 28 and later 39 genes were identified as candidates for unique fetal cell markers. More than half of these are genes known to be expressed in the placenta, especially in trophoblast cells [24, 25].

\section{Next Generation Sequences (NGS)}

Nowadays, NGS is a critical technology in prenatal diagnosis of fetal chromosomal aberrations. From August 2011 non-invasive prenatal test (NIPT) has been introduced in Hong Kong and later in the United States [24]. NIPT provides an intermediate step between maternal serum 
screening and invasive diagnostic testing of fetal chromosomal abnormalities during early embryogenesis $[18,50]$. NIPT implicates analyzing the cffDNA present in a sample of maternal blood. The whole-genome sequencing [90-94], targeted genome sequencing [95-97], single nucleotide polymorphism (SNP)-based sequencing [98-100] are commercially available NIPT approaches for today.

In 2014 the first commercial test MaterniT21Plus ${ }^{\mathrm{TM}}$ based on NIPT technology was presented by Sequenom (USA). The basic test detects trisomy $13,16,18,21,22, X, Y$ along with determination of paternity, fetal sex, and some microdeletions. NIPT produces low false positives values (1-3\%) and can be implemented in prenatal medicine as a replacement for invasive testing. In the US, test prices range from $\$ 795$ to over $\$ 3,000[18]$.

The non-invasive prenatal aneuploidy test, called the NIFTYTM (NonInvasive Fetal TrisomY test), was offered to pregnant women as a form of Down syndrome screening by the Chinese company BGI. The NIFTYTM can be applied any time after 12 gestation weeks for women with no previous pregnancy history. A low false positive rate of results has been shown. However, the NIFTYTM screening program requires further evaluation, specifically in terms of its cost-effectiveness [32].

\section{CONCLUSION}

For a long time an invasive prenatal diagnosis of chromosomal aberration have been based on fetal genetic material analysis by chorionic villus sampling, amniocentesis, placental biopsy or cordocentesis. Invasive methods were not replaceable by non-invasive approaches. Nowadays, maternal venous blood is an alternative source of fetal genetic material. However, there are not enough FCs for karyotyping in the maternal blood during normal pregnancy. Consequently, a variety of approaches of enriching FCs in a maternal blood sample for fetal genetic disorders diagnosis have been developed.

Until quite recently it was assumed that fetal nucleated red blood cells are the target cell type of choice in maternal blood for cell culture and non-invasive prenatal genetic diagnosis. However, the fetal erythroblasts from maternal blood not well proliferate in vitro comparing with fetal erythroblasts from chorionic villi. Thus, searching of fetal erythroblasts culture conditions plays a crucial role. It is shown that fetal endothelial precursors are able to replace maternal endothelial cells during early embryogenesis. Fetal endothelial progenitor cells as a non-invasive cell source for analysis of chromosome aberration has been described. Although further methods of selection of fetal endothelial precursor cells from maternal cells in vitro must be provided. Fetal multipotent mesenchymal stem cells are viewed as an alternative source of stem cells for regenerative medicine.

FISH and PCR based on Y-chromosome detection are the most frequently used approaches for FCs enrichment from maternal blood. However, quantification of $Y$ chromosome DNA is informative tool in experimental studies but cannot be commonly used for prenatal diagnosis of chromosomal aberrations for both sexes. Detection of non-shared HLA fetus polymorphisms among maternal genetic material is an applicable method in clinical practice.

NIPT is an advance in the detection of fetal genetic material that analyzes cffDNA in the blood of a pregnant woman. This approach allowed a low frequency of false-positive results in clinical practice along with high sensitivity and reliability. However, in terms of cost efficiency, this test requires further evaluation. The comprehensive price will make NIPT more accessible for population. The development of new approaches in gene sequencing with lower cost for prenatal screening makes this method proper to be applied in chromosomal aberrations as well as genetic disorders.

However, the identification of circulating FCs markers in the maternal blood is still necessary to be fully assessed and applied for both prenatal diagnosis and fundamental research in transplantology and regenerative medicine.

\section{REFERENCES}

1. Firth HV, Boyd PA, Chamberlain PF, et al. Analysis of limb reduction defects in babies exposed to chorionic villus sampling. Lancet. 1994; 343(8905): 1069-71

2. Kollmann M, Haeusler M, Haas J, et al. Procedure-related complications after genetic amniocentesis and chorionic villus sampling. Ultraschall. Med. 2013; 34(4): $345-48$.

3. Tabor A, Philip J, Madsen M, et al. Randomised controlled trial of genetic amniocentesis in 4606 low-risk women. Lancet. 1986; 1(8493): $1287-93$.

4. Norwitz ER, Levy B. Noninvasive prenatal testing: the future is now. Rev. Obstet. Gynecol. 2013; 6(2): 48-62.

5. Migliaccio G, Migliaccio AR, Petti S, et al. Human embryonic hemopoiesis. Kinetics of progenitors and precursors underlying the yolk sac-liver transition. J Clin Invest. 1986; 78(1): 51-60.

6. Thomas MR, Williamson R, Craft I, et al. Y chromosome sequence DNA amplified from peripheral blood of women in early pregnancy. Lancet. 1994; 343(8894): 413-14.

7. Millar DS, Davis $L R$, Rodeck CH, et al. Normal blood cell values in the early mid-trimester fetus. Prenat Diagn.1985; 5(6): 367-73.

8. de Waele M, Foulon W, Renmans W, et al. Hematologic values and lymphocyte subsets in fetal blood. Am J Clin Pathol. 1988; 89(6): 742-46.

9. Forestier F, Daffos F, Catherine N, et al. Developmental hematopoiesis in normal human fetal blood. Blood.1991; 77(11): 2360-63.

10. Ariga $\mathrm{H}$, Ohto $\mathrm{H}$, Busch MP, et al. Kinetics of fetal cellular and cell-free DNA in the maternal circulation during and after pregnancy: implications for noninvasive prenatal diagnosis. Transfusion. 2000; 41(12): 1524-30.

11. Lo YM, Lau TK, Chan LY, et al. Quantitative analysis of the bidirectional fetomaternal transfer of nucleated cells and plasma DNA. Clin. Chem. 2000; 46(9):1301-09.

12. Campagnoli C, Roberts IA, Kumar $S$, et al. Identification of mesenchymal stem/progenitor cells in human first-trimester fetal blood, liver, and bone marrow. Blood. 2001; 98(8): 2396-402. 
13. Mikhail MA, M'Hamdi H, Welsh J, et al. High frequency of fetal cells within a primitive stem cell population in maternal blood. Hum Reprod. 2008 ; 23(4): 928-33.

14. Khosrotehrani $K$, Johnson KL, Cha DH, et al. Transfer of fetal cells with multilineage potential to maternal tissue. JAMA. 2004; 292(1): 75-80.

15. Pritchard S, Hoffman AM, Johnson KL, et al. Pregnancy-associated progenitor cells: an under-recognized potential source of stem cells in maternal lung. Placenta. 2011; 32(4): 298-303.

16. Bianchi DW. Fetomaternal cell traffic, pregnancy-associated progenitor cells, and autoimmune disease. Best Pract Res Clin Obstet Gynaecol. 2004; 18(6): 959-75.

17. Pineda-Krch M, LehtiläK. Costs and benefits of genetic heterogeneity within. J Evol Biol. 2004; 17(6): 1167-77.

18. Allyse M, Minear MA, Berson E, et al. Non-invasive prenatal testing: a review of international implementation and challenges. Int J Womens Health. 2015; 16(7): 113-26.

19. Ho SS, O'Donoghue K, Choolani M. Fetal cells in maternal blood: state of the art for non-invasive prenatal diagnosis. Ann Acad Med Singapore. 2003 ; $32(5): 597-603$.

20. Iverson GM, Bianchi DW, Cann HM, et al. Detection and isolation of fetal cells from maternal blood using the flourescence-activated cell sorter (FACS). Prenat Diagn. 1981; 1(1): 61-73.

21. Tavian M, Coulombel L, Luton D, et al. Aorta-Associated CD34+ Hematopoietic Cells in the Early Human Embry. Blood. 1996; 87(1): 67-72.

22. Nierhoff $D$, Levoci L, Schulte $S$, et al. New cell surface markers for murine fetal hepatic stem cells identified through high density complementary DNA microarrays. Hepatology. 2007; 46(2): 535-47.

23. Pritchard S, Wick H, Slonim D, et al. Comprehensive Analysis of Genes Expressed by Rare Microchimeric Fetal Cells in the Maternal Mouse Lung. Biol Reprod. 2012; 87(2): 42. doi:10.1095/biolreprod.112.101147

24. Brinch $M$, Hatt $L$, Singh $R$, et al. Identification of circulating fetal cell markers by microarray analysis. Prenat Diagn. 2012; $32(8): 742-51$.

25. Hatt $L$, Brinch $M$, Singh $R$, et al. Characterization of fetal cells from the maternal circulation by microarray gene expression analysis--could the extravillous trophoblasts be a target for future cell-based non-invasive prenatal diagnosis? Fetal Diagn Ther. 2013; 35(3): 218-27.

26. Hatt L, Brinch M, Singh R, et al. A new marker set that identifies fetal cells in maternal circulation with high specificity. Prenat Diagn. $2014 ;$ 34(11): 1066-72.

27. Sipos $P I$, Rens $W$, Schlecht $H$, et al. Uterine vasculature remodeling in human pregnancy involves functional macrochimerism by endothelial colony forming cells of fetal origin. Stem Cells. 2013; 31(7): 1363-70.

28. Mahmood U, O'Donoghue K. Microchimeric fetal cells play a role in maternal wound healing after pregnancy. Chimerism. $2014 ; \mathbf{5 ( 2 ) : ~} 40-52$.

29. Cirello V, Rizzo R, Crippa M, et al. Fetal cell microchimerism: a protective role in autoimmune thyroid diseases. Eur J Endocrinol. 2015; 173(1): 111-18.

30. Covone AE, Kozma R, Johnson PM, et al. Analysis of peripheral maternal blood samples for the presence of placenta-derived cells using Y-specific probes and McAb H315. Prenat Diagn. 1988; 8(8): 591-607.

31. Committee Opinion No. 581: the use of chromosomal microarray analysis in prenatal diagnosis. Obstet Gynecol. 2013; 122(581): 1374-1377. doi: 10.1097/01. AOG.0000438962.16108.d1

32. Lau TK, Chan MK, Lo PS, et al. Clinical utility of noninvasive fetal trisomy (NIFTY) test - early experience. The Journal of Maternal-Fetal and Neonatal Medicine. 2012; 25(10): 1856-59.

33. Manegold-Brauer G, Kang Bellin A, Hahn S, et al. A new era in prenatal care: non-invasive prenatal testing in Switzerland. Swiss Med Wkly. 2014 ; 4(144): w13915.

34. Debeljak M, Freed DN, Welch JA, et al. Haplotype counting by next-generation sequencing for ultrasensitive human DNA detection. J Mol Diagn. 2014 ; 16(5): 495-503.

35. Everett TR, Chitty LS. Cell-free fetal DNA: the new tool in fetal medicine. Ultrasound Obstet Gynecol. 2015; 45(5): 499-507.

36. Xu XP, Gan HY, Li FX, et al. A Method to Quantify Cell-Free Fetal DNA Fraction in Maternal Plasma Using Next Generation Sequencing: Its Application in Non-Invasive Prenatal Chromosomal Aneuploidy Detection. PLoS One. 2016; 11(1): e0146997.

37. Goodfellow CF, Taylor PV. Extraction and identification of trophoblast cells circulating in peripheral blood during pregnancy. Br J 0bstet Gynaecol. - 1982; 89(1): 65-68.

38. Chua S, Wilkins T, Sargent I, et al. Trophoblast deportation in pre-eclamptic pregnancy. Br J Obstet Gynaecol. 1991; 98(10): 973-79.

39. Szwajcowska M, Kalinka J, Krajewski P. Nucleated red blood cells (nRBC) as an auxiliary marker of intrauterine infection. J Ped Neonatal. 2005; 2(1): 15-18.

40. Gänshirt D, Garritsent H, Holzgreve W, et al. Fetal cells in maternal blood. Curr. Opin. Obstet. Gyn. 1995; 7(2): 103-8.

41. Nguyen HS, Dubernard G, Aractingi S, et al. Feto-maternal cell trafficking: a transfer of pregnancy associated progenitor cells. Stem Cell Rev. 2006; 2(2): 111-16.

42. Bianchi DW, Zickwolf GK, Weil GJ, et al. Male fetal progenitor cells persist in maternal blood for as long as 27 years postpartum. Proc Natl Acad Sci USA. 1996; 93(2): 705-8.

43. Khosrotehrani K, Reyes RR, Johnson KL, et al. Fetal cells participate over time in the response to specific types of murine maternal hepatic injury. Hum Reprod. 2007; 22(3): 654-61.

44. Covone AE, Mutton D, Johnson PM, et al. Trophoblast cells in peripheral blood from pregnant women. Lancet.1984; 2(8407): 841-43.

45. Hengstschläger M, Bernaschek G. Fetal cells in the peripheral blood of pregnant women express thymidine kinase: a new marker for detection. FEBS Lett.1997; 404(23): 299-302.

46. Sargent JL, Johansen M, Chua S, et al. Clinical Experience: Isolating Trophoblasts from Maternal Blood. Annals of the New York Academy of Sciences. 1994; 731(1): 154-61.

47. Goldberg JD, Wohlferd MM. Incidence and outcome of chromosomal mosaicism found at the time of chorionic villus sampling. Am J Ohstet Gynecol. 1997; 176(6): 1349-52.

48. Henderson KG, Shaw TE, Barrett IJ, et al. Distribution of mosaicism in human placentae. Hum Genet.1996; 97(5): 650-54.

49. Benirschke K, Willes L. Deportation of trophoblastic emboli to maternal lung. A source of cell-free DNA in maternal blood? Chimerism. 2010; 1(1): 15-18.

50. Manegold-Brauer G, Hahn S, Lapaire 0. What does next-generation sequencing mean for prenatal diagnosis? Biomark Med. $2014 ; 8(4): 499-508$.

51. Huyhn A, Dommergues M, Izac B, et al. Characterization of hematopoietic progenitors from human yolk sacs and embryos. Blood. 1995; 86(12): 4474-85.

52. Loken MR, Civin Cl, Bigbee WL, et al. Coordinate glycosylation and cell surface expression of glycophorin A during normal human erythropoiesis. Blood.1987; 70(6): 1959-61. 
53. Bianchi DW, Flint AF, Pizzimenti MF, et al. Isolation of fetal DNA from nucleated erythrocytes in maternal blood. Proc Natl Acad Sci USA. 1990; 87(9): 3279-83

54. Zheng YL, Demaria $M$, Zhen $D$, et al. Flow sorting of fetal erythroblasts using intracytoplasmic anti-fetal haemoglobin: preliminary observations on maternal samples. Prenat Diagn. 1995; 15(10): 897-905.

55. Mesker WE, Ouwerkerk-van Velzen MC, Oosterwijk JC, et al. Two-colour immunocytochemical staining of gamma (gamma) and epsilon (epsilon) type haemoglobin in fetal red cells. Prenat Diagn. 1998; 18(11): 1131-37.

56. Bianchi DW. Fetal cells in the maternal circulation: feasibility for prenatal diagnosis. British J Haematol. 1999. 105(3): 574-83.

57. van Wijk IJ, van Vugt JM, Mulders MA, et al. Enrichment of fetal trophoblast cells from the maternal peripheral blood followed by detection of fetal deoxyribonucleic acid with a nested X/Y polymerase chain reaction. Am J Obstet Gynecol. 1996. 174(3): 871-78.

58. Pearson HA. Life-span of the fetal red blood cell. The Journal of Pediatrics. 1967; 70(2): 166-71.

59. Simpson JL, Elias S. Isolating fetal cells in maternal circulation lor prenatal diagnosis . Prenat Diagn. 1994; 14(13): 1229-1242.

60. Choolani M, O'Donoghue $K$, Talbert D, et al. Characterization of first trimester fetal erythroblasts for non-invasive prenatal diagnosis. Mol Hum Reprod. 2003; 9(4): 227-235.

61. Price JO, Elias S, Wachtel SS. Prenatal diagnosis with fetal cells isolated from maternal blood by multiparameter flow cytometry. Am J Obstet Gynecol. 1991; 165(6Pt1): 1731-37.

62. Troeger C, Holzgreve W, Hahn S. A comparison of different density gradients and antibodies for enrichment of fetal erythroblasts by MACS. Prenat. Diagn. 1999; 19(6): $521-26$

63. Al-Mufti R, Hambley H, Farzaneh F, et al. Distribution of fetal and embryonic hemoglobins in fetal erythroblasts enriched from maternal blood. Haematologica. 2001; 86(4): 357-62

64. Kølvraa S, Christensen B, Lykke-Hansen L, et al. The Fetal Erythroblast Is Not the Optimal Target for Non-invasive Prenatal Diagnosis: Preliminary Results. J Histochem Cytochem. 2005; 53(3): 331-36.

65. Walknowska J, Conte FA, Grumbach MM. Practical and theoretical implications of fetal-maternal lymphocyte transfer. Lancet. 1969; 1(7606): 1119-22.

66. Herzenberg LA, Bianchi DW, Schröder J, et al. Fetal cells in the blood of pregnant women: detection and enrichment by fluorescence-activated cell sorting. Proc. Natl. Acad. Sci. USA. 1979; 76(3): 1453-55.

67. Sunami R, Komuro $M$, Tagaya $H$, et al. Migration of microchimeric fetal cells into maternal circulation before placenta formation. Chimerism. 2010; 1(2): 66-8.

68. Sunami $R$, Komuro $M$, Yuminamochi $T$, et al. Fetal cell microchimerism develops through the migration of fetus-derived cells to the maternal organs early after implantation. J Reprod Immunol. 2010; 84(2): 117-23.

69. Wang $Y$, Iwatani $H$, Ito $T$, et al. Fetal cells in mother rats contribute to the remodeling of liver and kidney after injury. Biochem Biophys Res Commun. 2004; 325(3): 961-67.

70. Tan XY, Liao H, Sun L, et al. Fetal microchimerism in the maternal brain: A novel population of fetal progenitor or stem cells able to cross the blood-brain barrier? Stem Cells. 2005; 23(10): 1443-52.

71. Rina Kara J, Bolli P, Karakikes I, et al. Fetal Cells Traffic to Injured Maternal Myocardium nd Undergo Cardiac Differentiation. Circulation Research. 2012; 110(1): 82-93.

72. Nguyen HS, Oster M, Uzan S. Maternal neoangiogenesis during pregnancy partly derives from fetal endothelial progenitor cells. Proc Natl Acad Sci USA. 2007; 104(6): $1871-76$.

73. Zhong JF, Weiner LP. Role of Fetal Stem Cells in Maternal Tissue Regeneration. Gene Regul Syst Bio. 2007; 1: 111-115.

74. O'Donoghue $K$, Choolani $M$, Chan J, et al. Identification of fetal mesenchymal stem cells in maternal blood: implications for non-invasive prenatal diagnosis. Mol Hum Reprod. 2003; 9(8): 497-502.

75. Kaufmann $P$, Black S, Huppertz B. Endovascular trophoblast invasion: implications for the pathogenesis of intrauterine growth retardation and preeclampsia. Biol Reprod. 2003; 69(1): 1-7.

76. Harris $L K$. Review: trophoblast-vascular cell interactions in early pregnancy: how to remodel a vessel. Placenta. 2010; S93-8. doi: 10.1016/j.placenta.2009.12.012

77. Zhou $Y$, Fisher SJ, Janatpour $M$, et al. Human cytotrophoblasts adopt a vascular phenotype as they differentiate. A strategy for successful endovascular invasion? J Clin Invest.1997; 99(9): 2139-51.

78. Gordon MY, Levicar N, Pai M, et al. Characterization and clinical application of human CD34+ stem/progenitor cell populations mobilized into the blood by granulocyte colony-stimulating factor. Stem Cells. 2006; 24(7): 1822-30.

79. Parant O, Dubernard G, Challier JC, et al. CD34+ cells in maternal placental blood are mainly fetal in origin and express endothelial markers. Lab Invest. 2009; 89(8): 915-23.

80. O'Donoghue $K$, Chan J, de la Fuente $J$, et al. Microchimerism in female bone marrow and bone decades after fetal mesenchymal stem-cell trafficking in pregnancy. Lancet. 2004; 364(9429): 179-82.

81. Guillot PV, Gotherstrom C, Chan J, et al. Human first-trimester fetal MSC express pluripotency markers and grow faster and have longer telomeres than adult MSC. Stem Cells. 2007; 25(3): 646-54.

82. Kennea NL, Waddington SN, Chan J, et al. Differentiation of human fetal mesenchymal stem cells into cells with an oligodendrocyte phenotype .Cell Cycle. 2009; 8(7): 1069-79.

83. Wu G, Schöler HR. Role of Oct4 in the early embryo development. Cell Regen (Lond). 2014; 3(1). doi: 10.1186/2045-9769-3-7

84. Zheng $S$, Tong $X, W u L$, et al. A comparison of in vitro culture of fetal nucleated erythroblasts from fetal chorionic villi and maternal peripheral blood for noninvasive prenatal diagnosis. Fetal Diagn Ther. 2012; 32(3): 194-200.

85. Risau W. Embryonic angiogenesis factors. Pharmacol Ther.1991; 51(3): 371-76.

86. Risau W, Flamme I. Vasculogenesis . Annu Rev Cell Dev Biol. 1995; 11: 73-91.

87. Gussin HA, Bischoff FZ, Hoffman R, et al. Endothelial precursor cells in the peripheral blood of pregnant women. J Soc Gynecol Investig. 2002; 9(6): 357-61.

88. Rafii S. Circulating endothelial precursors: mystery, reality, and promise. J Clin Invest. 2000; 105(1): 17-19.

89. Gussin HA, Elias S. Culture of fetal cells from maternal blood for prenatal diagnosis. Hum Reprod Update. 2002; 8(6): 523-27. 
90. Lo YM, Tein MS, Lau TK, et al. Quantitative analysis of fetal DNA in maternal plasma and serum: implications for noninvasive prenatal diagnosis. Am. J. Hum. Genet. 1998; 62(4): 768-75

91. Van der Schoot CE, Hahn S, Chitty LS Non-invasive prenatal diagnosis and determination of fetal Rh status. Semin. Fetal Neonatal Med. 2008 ; 13(2): 63-8.

92. Ehrich M, Deciu C, Zwiefelhofer $T$, et al. No-ninvasive detection of fetal trisomy 21 by sequencing of DNA in maternal blood: a study in a clinical setting. Am. J. Obstet. Gynecol. 2011; 204(3): 205.e1-11.

93. Palomaki GE, Kloza EM, Lambert-Messerlian GM, et al. DNA sequencing of maternal plasma to detect Down syndrome: an international clinical validation study. Genet Med. 2011; 13(11): 913-20.

94. Bianchi DW, Platt LD, Goldberg JD, et al. Genome-wide fetal aneuploidy detection by maternal plasma DNA sequencing. Obstet. Gynecol. $2012 ; 119(5): 890-901$.

95. Sparks $A B$, Struble $C A$, Wang $E T$, et al. Non-invasive prenatal detection and selective analysis of cell-free DNA obtained from maternal blood: evaluation for trisomy 21 and trisomy 18. Am. J. Obstet. Gynecol. 2012; 206(4): 319.e1-9.

96. Ashoor G, Syngelaki A, Wagner M, et al. Chromosome-selective sequencing of maternal plasma cell-free DNA for first-trimester detection of trisomy 21 and trisomy 18. Am. J. Obstet. Gynecol. 2012; 206(4): 322.e1-5.

97. Norton ME, Brar H, Weiss J, et al. Non-Invasive Chromosomal Evaluation (NICE) Study: results of a multicenter prospective cohort study for detection of fetal trisomy 21 and trisomy 18. Am. J. Obstet. Gynecol. 2012; 207(2): 137.e1-8.

98. Zimmermann B, Hill M, Gemelos $G$, et al. Noninvasive prenatal aneuploidy testing of chromosomes $13,18,21, \mathrm{X}$, and $\mathrm{Y}$, using targeted sequencing of polymorphic loci. Prenat Diagn. 2012; 32(13): 1233-41.

99. Nicolaides $\mathrm{KH}$, Syngelaki $A$, Gil $M$, et al. Validation of targeted sequencing of single-nucleotide polymorphisms for non-invasive prenatal detection of aneuploidy of chromosomes 13, 18, 21, X, and Y. Prenat. Diagn. 2013; 33(6): 575-79.

100. Samango-Sprouse C, Banjevic M, Ryan A, et al. SNP-based non-invasive prenatal testing detects sex chromosome aneuploidies with high accuracy. Prenat. Diagn. 2013; 33(7): 643-49.

年

The author indicates no potential conflicts of interest.

Received: December 02, 2015

Accepted: May 25, 2016 